\title{
Analisis Performansi Antena Yagi-Uda 11 Elemen Sebagai Penguat Sinyal Global System For Mobile Communication (GSM)
}

\author{
Tanridio Silviati Delfina Abdurrahman ${ }^{1}$, Andi Muhammad Saad ${ }^{2}$ dan Bulgis $^{3}$ \\ ${ }^{1,2}$ Teknik Elektro, Fakultas Teknik, Universitas Muslim Indonesia \\ ${ }^{3}$ Teknik Sipil, Fakultas Teknik, Universitas Muslim Indonesia \\ Email : tanridio@yahoo.com.au, saadmuh503@yahoo.com,bulgis100470@gmail.com.
}

\begin{abstract}
Limited telecommunication network services, even for $2 G$ technology, in some regions due to living in small islands, range of hills and blank spot areas are experienced in Indonesian Republic. One of solutions is proposed by using 11-element YagiUda antenna operated in GSM band of frequencies. Mmanagal software is run to simulate this proposed model in order to analyze antenna performance parameters namely field pattern, $F / B$ ratio, gain antenna, input impedance and SWR. First of all, the antenna performance, operated at frequency of $925 \mathrm{MHz}$, is the best because of the ideal SWR. Furthermore, the performance parameters of the antenna at GSM's uplink frequency, $902.5 \mathrm{MHz}$, are good because the SWR value is less than 2 dB. However, drawback of the antenna performance is occurred in which the model antenna is operated at central frequency of GSM downlink, $947.5 \mathrm{MHz}$. It is stated that radiated pattern, back lobe is more dominant than main lobe, is vice versa with two other operated frequencies. Moreover, the value of $S W R$, slightly above $4.6 \mathrm{~dB}$, is more than $2 \mathrm{~dB}$.
\end{abstract}

Keyword : Yagi-Uda antenna, field pattern, SWR, Mmanagal software.

\section{Pendahuluan}

Global system for mobile communication (GSM) merupakan generasi kedua dari perkembangan jaringan telekomunikasi yang menitikberatkan pada komunikasi suara. Saat ini, perkembangan telekomunikasi di dunia telah menerapkan teknologi telekomunikasi generasi keempat (4G). Implementasi teknologi $4 \mathrm{G}$ belum merata di seluruh wilayah Republik Indonesia, masih banyak daerah yang hanya dilayani oleh jaringan $2 \mathrm{G}$, terutama daerah-daerah kepulauan. Band frekuensi yang bekerja pada sistem GSM adalah 890 - 915 MHz arah uplink dan 935 - $960 \mathrm{MHz}$ arah downlink. Layanan telekomunikasi belum sepenuhnya dapat dinikmati oleh masyarakat di daerah kepulauan, bahkan untuk teknologi $2 \mathrm{G}$ sekalipun. Oleh karena itu dibutuhkan alat bantu untuk dapat menangkap sinyal telekomunikasi pada daerah-daerah blank spot. Antena Yagi-Uda dapat menjadi solusi meretas keterbatasan jaringan telekomunikasi di remote area.

Antena Yagi-Uda yang lebih popular dikenal sebagai antenna yagi pertama kali ditemukan oleh Proessor Yagi dan Uda di tahun 1926. Antena Yagi adalah sebuah antenna yang pola pancaran radiasinya bersifat direksional. Tipe antenna
Yagi umumnya dipergunakan untuk transmisi data dan antenna penerimaan siaran televisi dan aplikasi lainnya yang sistemnya beroperasi pada band frekuensi HF, VHF dan UHF [1 - 2]. Antena ini terdiri atas beberapa elemen berupa satu buah reflector, satu buah driven dan satu atau lebih director. Ketiga elemen tersebut terhubung oleh sebuah boom. Struktur antenna Yagi dengan 11 elemen dapat dilihat pada gambar di bawah ini.

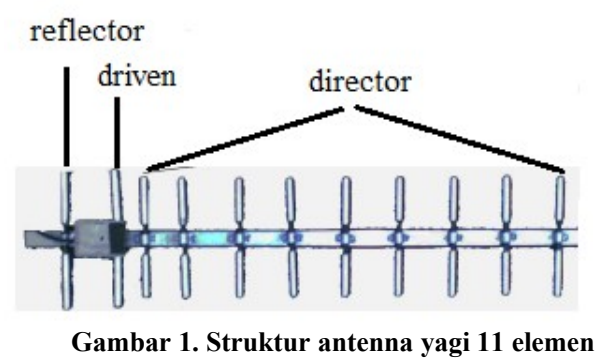

Salah satu contoh 11-elemen antenna Yagi yang diimplementasikan NBS untuk frekuensi $400 \mathrm{MHz}$, diameter elemen sebesar $0,0085 \lambda$, panjang reflector $0,482 \lambda$, panjang driven $0,432 \lambda$, panjang ke sembilan director berturut-turut sebesar $0,415 \lambda, 0,407 \lambda, 0,398 \lambda, 0,390 \lambda, 0,390 \lambda, 0,390 \lambda$, $0,390 \lambda, 0,398 \lambda$ dan $0,407 \lambda[4]$.

Parameter-parameter performansi antenna dinyatakan dalam pancaran pola radiasi, SWR, perbandingan $\mathrm{F} / \mathrm{B}$, dan impedansi input. Pola radiasi merupakan sifat arah pancar radiasi suatu antenna pada arah tertentu. Nilai SWR mencerminkan kehandalan antenna bekerja pada suatu frekuensi. Perbandingan F/B menyatakan perbandingan arah pancar utama (main lobe) suatu antenna terhadap arah pancar sebaliknya (back lobe). Sedangkan impedansi input diperoleh dengan membandingkan tegangan dan arus pada titik catu terminal antenna.

\section{Simulasi Antena Yagi 11 Elemen}

Antena yagi dengan 11 elemen yang terdiri atas satu elemen reflector, satu elemen driven dan sembilan elemen director. Desain antenna Yagi 11 elemen ini memiliki spesifikasi yang bekerja pada band frekuensi GSM dapat dilihat pada table berikut ini. 
Tabel 1. Spesifikasi antenna Yagi 11-elemen

\begin{tabular}{|l|l|}
\hline \multicolumn{1}{|c|}{ ITEM } & \multicolumn{1}{c|}{ SPESIFIKASI } \\
\hline Diameter elemen & $0,019 \lambda$ \\
\hline Panjang boom & $2,621 \lambda$ \\
\hline Panjang reflector & $0,481 \lambda$ \\
\hline Panjang driven & $0,447 \lambda$ \\
\hline Panjang Director D1 & $0,442 \lambda$ \\
\hline Panjang Director D2 & $0,416 \lambda$ \\
\hline Panjang Director D3 & $0,377 \lambda$ \\
\hline Panjang Director D4 & $0,101 \lambda$ \\
\hline Panjang Director D5 & $0,392 \lambda$ \\
\hline Panjang Director D6 & $0,379 \lambda$ \\
\hline Panjang Director D7 & $0,365 \lambda$ \\
\hline Panjang Director D8 & $0,384 \lambda$ \\
\hline Panjang Director D9 & $0,360 \lambda$ \\
\hline Jarak Reflector - Driven & $0,064 \lambda$ \\
\hline Jarak Driven - D1 & $0,044 \lambda$ \\
\hline Jarak D1 - D2 & $0,011 \lambda$ \\
\hline Jarak D2 - D3 & $0,120 \lambda$ \\
\hline Jarak D3 - D4 & $0,020 \lambda$ \\
\hline Jarak D4 - D5 & $0,131 \lambda$ \\
\hline Jarak D5 - D6 & $0,112 \lambda$ \\
\hline Jarak D6 - D7 & $0,078 \lambda$ \\
\hline Jarak D7 - D8 & $0,106 \lambda$ \\
\hline Jarak D8 - D9 & $0,104 \lambda$ \\
\hline
\end{tabular}

Software mmanagal merupakan salah satu alat analisis antenna berdasarkan metoda momen. Mmanagal dipergunakan untuk mensimulasikan antenna Yagi 11 elemen dengan spesifikasi elemen seperti yang tertera pada table 1. Software ini dapat menampilkan struktur geometris (model) antenna, dimensi setiap elemen dan jarak antarelemen, perbandingan pola pancaran Front dan Back, SWR, penguatan dan pola radiasi antenna. Berdasar scenario pada table di atas, model antenna dapat diperoleh seperti pada gambar 2 berikut ini. Desain antenna yagi 11 elemen akan disimulasikan untuk frekuensi $925 \mathrm{MHz}$, frekuensi tengah band frekuensi uplink dan band frekuensi downlink GSM yaitu $902.5 \mathrm{MHz}$ dan 947,5 Mhz.

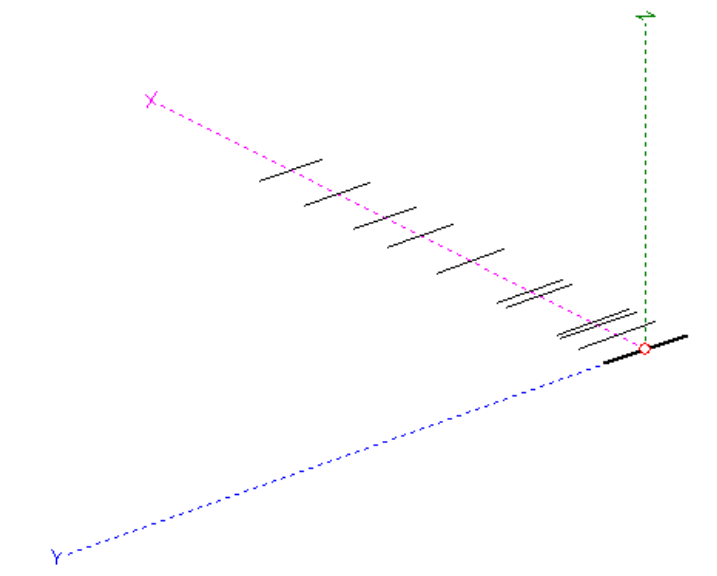

Gambar 2. Struktur Geometri Scenario Antena Yagi 11 elemen

\section{Hasil dan Pembahasan}

Struktur geometri kesebelas elemen pada desain antenna secara detail ditampilkan pada gambar 3 di bawah ini.

\begin{tabular}{|c|c|c|c|c|c|c|}
\hline "Wir & & & & & & \\
\hline 11 & & & & & & \\
\hline 0.7874, & -0.05838 & 0.0 & 0.7874, & 0.05838 & 0.0 & 0.003, \\
\hline 0.6838, & -0.06225 & 0.0 & 0.6838 & 0.06225 & 0.0 & 0.003, \\
\hline 0.5782, & -0.0592 & 0.0 & 0.5782 & 0.0592 & 0.0 & 0.003 \\
\hline 0.5006, & -0.0614 & 0.0 & 0.5006, & 0.0614, & 0.0 & 0.003, \\
\hline D.389, & -0.0635 & 0.0 & 0.389, & 0.0635 , & 0.0 & 0.003, \\
\hline 0.2584, & -0.0613 & 0.0 & 0.2584, & 0.0613, & 0.0 & 0.003, \\
\hline 0.2388, & -0.0612 & 0.0 & 0.2388, & 0.0612 & 0.0 & 0.003, \\
\hline 0.1196, & -0.0674 & 0.0 & 0.1196, & 0.0674, & 0.0 & 0.003, \\
\hline D.0639, & -0.07255 & 0.0 & 0.0639 & 0.07255 & 0.0 & 0.003, \\
\hline 0.108, & -0.0717 , & 0.0 & 0.108, & 0.0717, & 0.0 & 0.003, \\
\hline 0.0 & -0.078 & 0.0 & 0.0 & 0.078, & 0.0 & 0.003, \\
\hline
\end{tabular}

Kolom pertama dan ketiga pada gambar di atas menyatakan jarak akumulatif elemen-elemen director dan driven terhadap elemen reflector pada arah sumbu X. Panjang tiap elemen dapat dilihat dari kolom kedua (yang menyatakan sumbu y negatif) dan kolom kelima (sumbu y positif). Sementara itu, kolom ketiga dan keenam menyatakan posisi tiap elemen berdasarkan sumbu $\mathrm{Z}$. Radius tiap elemen terlihat pada kolom ketujuh dan kolom terakhir menyatakan metode segmentasi standar.

Hasil simulasi untuk frekuensi $925 \mathrm{MHz}$ dapat dilihat pada gambar 3 dan 4 . Gambar 3 memperlihatkan pola radiasi antenna yagi 11 elemen pada bidang horizontal ( $\mathrm{H}-$ Plane) dan vertikal (E - Plane) dengan frekuensi-frekuensi kerja 917, 921, 925, 929 dan $933 \mathrm{MHz}$. Pola radiasi yang berwarna biru mewakili frekuensi $925 \mathrm{MHz}$ memperliharkan nilai penguatan antenna dan perbandingan pancaran Front terhadap Back (F/B) yang paling besar diantara kelima frekuensi tersebut dengan nilai berturut-turut 18,1 dBi dan 19,1 dB. Pada gambar tersebut terlihat pula besar impedansi masukan pada antenna berrekuensi kerja $925 \mathrm{MHz}$ sebesar 17,7 $\Omega$. Sementara itu, gambar 4 menampilkan nilai SWR sebesar 1 untuk frekuensi $925 \mathrm{MHz}$. Nilai SWR 1 menandakan antenna ini dapat menerima semua daya yang diradiasiakan oleh antenna pemancar (match).

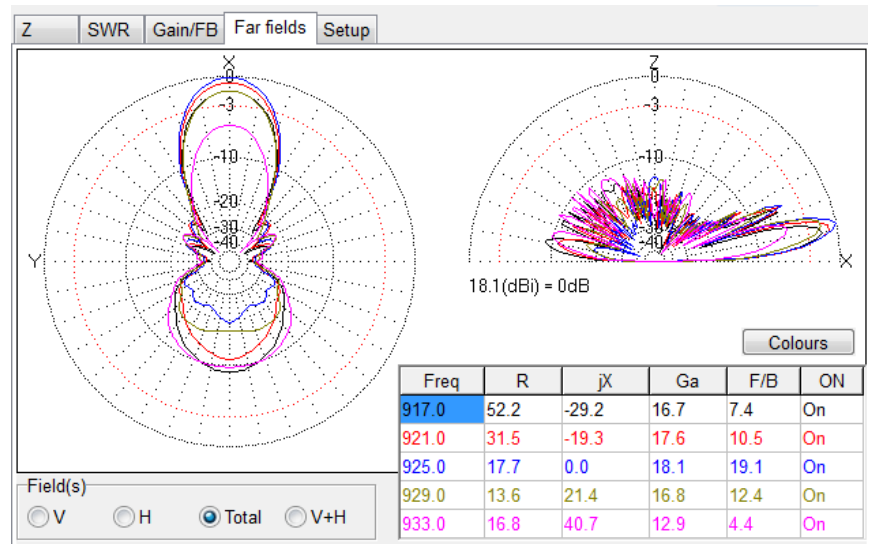

Gambar 4. Pola radiasi antenna yagi 11 elemen untuk frekuensi 917 $933 \mathrm{MHz}$. 


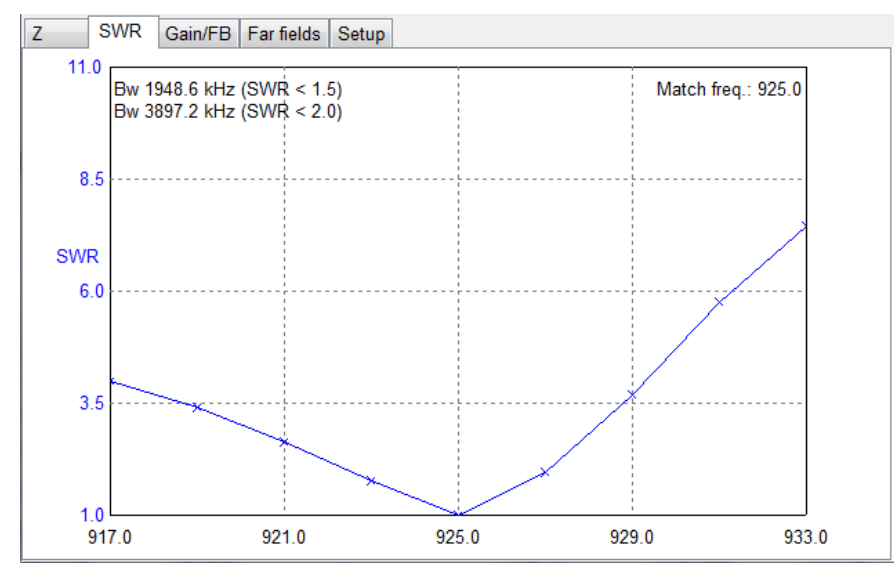

Gambar 5. Nilai SWR antenna yagi 11 elemen untuk rentang frekuensi $917-933 \mathrm{MHz}$

Hasil simulasi untuk frekuensi tengah $(902,5 \mathrm{MHz})$ dari band frekuensi uplink GSM terlihat pada gambar 5 dan 6 . Parameter performansi yang tampak dari kedua gambar 5 dan 6 memperlihatkan pola radiasi antenna yang sudah tidak direksional menuju main lobe. Terlihat bahwa pancaran back lobe hampir sebanding dengan kuat pancar main lobe. Impedansi masukannya bersifat kapasitif sebesar $(90,6-\mathrm{j}$ 3,7) $\Omega$. Sedangkan besar SWR masih dikategorikan baik karena nilai $\mathrm{SWR} \leq 2 \mathrm{~dB}$.

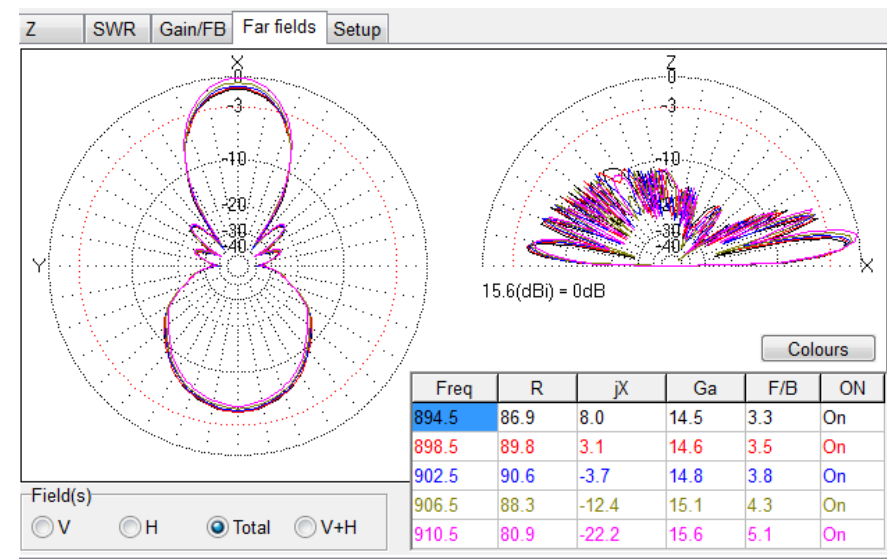

Gambar 6. Pola radiasi antenna yagi 11 elemen untuk band frekuensi uplink GSM

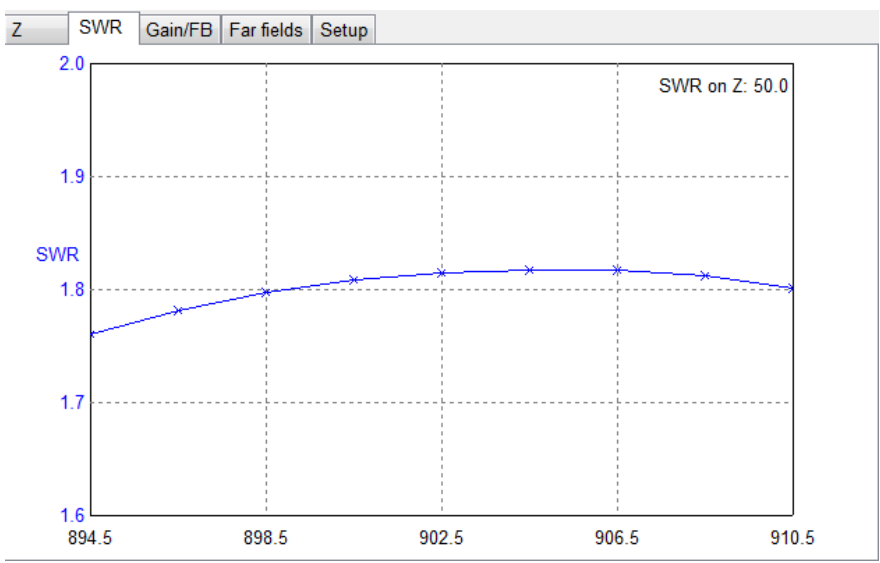

Gambar 7. Nilai SWR antenna yagi 11 elemen untuk band frekuensi uplink GSM
Hasil simulasi untuk frekuensi tengah dari band frekuensi downlink GSM yaitu 947,5 MHz tampak dari gambar 7 dan 8 berikut ini. Tampilan performansi antenna yagi yang disimulasikan pada frekuensi 947,5 MHZ tersaji pada gambar 7 dan gambar 8. Berdasarkan kedua gambar tersebut, pola radiasi antenna menuju arah sumbu $\mathrm{x}$ negatif (arah direksional antenna pada frekuensi ini dominan ke arah back lobe). Impedansi masukannya bersifak induktif sebesar $(46,1+\mathrm{j} 81,1) \Omega$. Sementara itu, nilai SWR yang diperoleh pada frekuensi uplink $\mathrm{SWR} \geq 2$, yang menandakan lebih banyak pola radiasi yang dipantulkan daripada yang diterima oleh antenna.

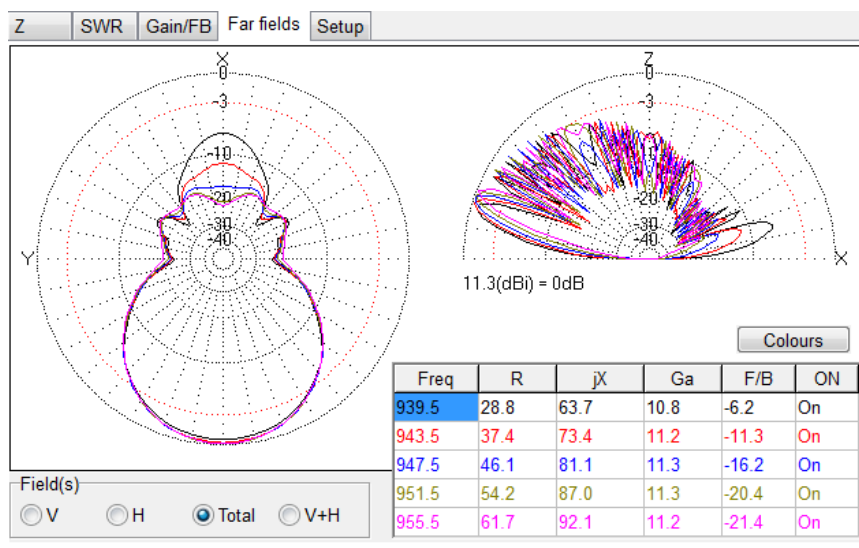

Gambar 8. Pola radiasi antenna yagi 11 elemen untuk band frekuensi downlink GSM

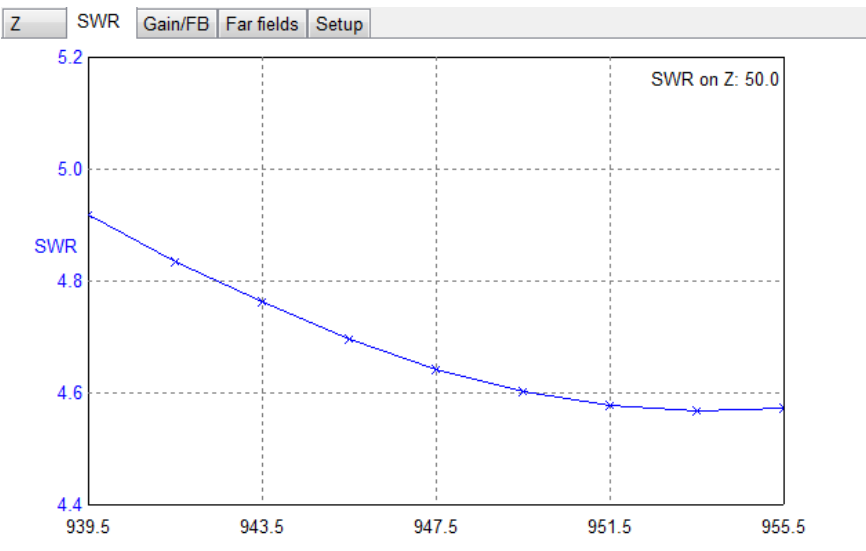

Gambar 9. Nilai SWR antenna yagi 11 elemen untuk band frekuensi downlink GSM

\section{KESIMPUlaN DAN SARAN}

\section{A. Kesimpulan}

Desain antenna yagi 11 elemen dengan spesifikasi sesuai table 1 berfungsi ideal pada frekuensi $925 \mathrm{MHz}$ dan masih beroperasi secara baik pada band frekuensi uplink GSM. Tetapi model antenna yagi ini buruk performansinya jika beroperasi di frekuensi downlink GSM.

\section{B. Saran}

Sebaiknya perlu optimasi desain antenna yagi 11 elemen ini supaya dapat bekerja baik di band frekuensi downlink GSM dan dilakukan pengukuran laboratorium untuk 
membandingkan hasil simulasi pemodelan dengan hasil pengukuran laboratorium.

\section{Daftar Pustaka}

[1] Cottony, H. V. 1956. High gain antennas for VHF scatter propagation. IRE Transaction on Communication System. 4 (1): 56 -63.

[2] Ebersbach, H., Thiel, D. V., and Leckenby, M. 2004. Modelling YagiUda antennas using point source approximation.Electronics Letter. 40 (18): $1095-1097$.

[3] Thiel, D.V. 2008. Exposure zones near parasitic elements in hign powered antennas. IEEE Antennas \& Propagation Symposium. San Diego, California. Hal 1 - 4.

[4] Viezbicke, P.P. 1976. Yagi Antenna Design, NBS Technical Note 688. Hal 7.

[5] Firdaus, Dewi, R., Vitria, R., Liwarda. 2012 Penguat sinyal GSM menggunakan antenna yagi 14 elemen. Elektron. 4 (1). 